\title{
Web: computing tool, business tool - Malaga firms in a case study
}

\author{
V. Fernández \& S. Millán \\ Department of Business Administration, ETEA-Cordoba University, \\ Spain
}

\begin{abstract}
Electronic commerce is a rising variable. The total value of transactions carried out through the Internet increases with each passing day. But this growth implies the development of web pages to support electronic commerce.

The aim of this work is to present the different stages of web page development found in companies in Malaga (Spain). Thus we analyse if the pages actually allow electronic commerce or are simply informative.

A total of 1,488 pages have been evaluated. Almost $80 \%$ of these firms limit their presence on Internet to strictly informative web pages provided by the telephone company.

A little over the remaining $20 \%$ have their own URL, but less than $13 \%$ of the total are active. So, only 190 pages appear in the final count.

Slightly over half of these 190 pages offer the products of the companies and allow some contact with the client, but 26 pages (13.58\%) are still only informative. Fully developed pages, from an electronic commerce point of view, amounted to under $6 \%$.

The present findings are far from allowing us to assert that most companies have implemented an electronic commerce system.

Unless most companies feel the need for being on Internet, they do not believe their presence to be a valuable commercial channel for them. Consequently, for the time being, only a minority of companies, and belonging to very concrete sectors, carry out fully electronic commerce.

Keywords: electronic commerce, web page design, case study.
\end{abstract}




\section{Introduction}

As shown in the "Estudio sobre comercio electrónico B2C 2004" (AECE [1]), elaborated by the Spanish Association of Electronic Commerce (AECE), the total number of Spanish internet clients has grown from 1.1\% between 2000 and 2001 , to $5.6 \%$ in 2002 , and to $3.8 \%$ in 2003 .

The same source indicates that total turnover increased more than $31.5 \%$ in 2003 as compared to 2002.

However, this trend is closely related to developments in the companies' web pages which hold the necessary tools for these transactions to take place.

For most companies, an informative web is frequently the way in which they introduce themselves into the world of Internet. For more effective electronic commerce, they will have to give the web pages further capacity to advance in the purchasing process. So, in addition to providing initial contact, they also will have to facilitate payment and delivery, and in a further step, maintenance and a personalized after-sales service.

More and more, companies will offer websites with all the capacities needed to allow comprehensive electronic commerce in a dynamic and effective way.

To back this proposal, the study of electronic commerce in Cordoba has already been presented, and now we present the corresponding one for Malaga.

This study shows the different levels in the development of the web pages belonging to Malaga business firms.

It will allow us to establish if those pages can be considered electronic commerce tools (business to commerce-B2C-), or are merely informative.

The aim of the informative page can be to promote the business's public image. But when a client gains access to Internet, he is looking for the maximum information possible, agility in obtaining it, the easiest way to make contact with the company, and the minimum response time. If our client does not get the expected results, this will damage the company's image instead of improving it.

\section{Methodology}

A relational database has been developed as the basis for a DBMS, considering all the variables in order to make up the statistical analysis.

First of all, the URL addresses of the companies in the city of Malaga have been collected. After that, all those pages have been studied and we have attempted to contact each company through its corresponding page.

\section{Targets}

$\checkmark \quad$ To determine the proportion of B2C webs belonging to each sector.

$\checkmark \quad$ To establish the number of companies encompassing the different electronic commerce levels in their web pages, differentiating between those companies working with physical products and those others working with virtual ones.

$\checkmark \quad$ To analyse the response time throughout the web. 
$\checkmark \quad$ To determine the update frequency of pages.

$\checkmark \quad$ To analyse the level of presence inside the web considering the number of visitors, the number of links from other pages, and the total amount of publicity for other companies found there.

$\checkmark \quad$ To study the observance of security rules to be able to pay for the product through the web.

$\checkmark \quad$ To establish the point to which client loyalty has been implanted.

$\checkmark \quad$ To determine a system to measure clients' loyalty.

$\checkmark \quad$ Analysis of additional services offered by the web.

\section{Levels of access to the web}

We may wonder if a business web is a commercial electronic web.

We can find the following:

$\checkmark \quad$ Webs informing about the company, whose content is made up of data about where the company is located, how it can be reached, what its history has been: Level 1 .

$\checkmark \quad$ Webs that publicise their products on the web: Level 2.

$\checkmark \quad$ Webs that also permit the client to get in contact with the company: Level 3.

$\checkmark \quad$ Webs that allow ordering: Level 4.

$\checkmark$ Webs that also involve the company in the delivery of the product: Level 5.

$\checkmark \quad$ Webs that allow actual payment: Level 6 .

There is a general tendency to classify as a commercial electronic web that type of business web that displays its products as if in a shop window without actually allowing a business transaction to take place there.

The Spanish Association of Electronic Commerce, in its report published in 2005 about the year 2004, found that electronic commerce in 2003 increased by $20 \%$ due to the increase in the number of internet visitors who buy through internet $(14 \%)$ as well as to the increase in the volume of purchase per client $(61 \%)$.

In the 2004 report, only $24 \%$ of the companies had a web, where the principle goals were company publicity ( $61 \%$ ) or the advertising of its products; only $22 \%$ were trying to attract clients and only $10 \%$ felt that the web could sell products or improve the attention to the client.

Of those that did sell their products through the web, only $34 \%$ had no problems with this process. The greatest difficulties found by the companies when selling through internet were: the lack of trust the clients showed for the form of payment $(25 \%)$, the unfamiliarity of the clients with this new means of doing business (17.5\%) and former shopping habits (14.3\%).

These results do not seem to agree with the theoretical assumptions of suppliers and demand expected from electronic commerce. According to this information the majority of companies do not have a web page, and those that do use it primarily to make themselves known. Whatever the objective of the 
company that is present on Internet, certain obligatory requirements at these points of sale must be met. That is, the web must:

$\checkmark \quad$ Be a DYNAMIC web, which saves time in both the offer and delivery of products.

$\checkmark$ Be a web that allows both clients and suppliers to SERVE THEMSELVES.

$\checkmark \quad$ Be a web that maintains the INTEGRATION of traditional business systems into the new environment.

$\checkmark \quad$ Be a web that applies e-intelligence systems (CRM) to provide the best possible client service.

\section{Results of the study; the report on Malaga}

\subsection{Data on the population and survey}

Once the levels and characteristics necessary for a commercial electronic web have been fixed, we are going to analyse to what point the web pages of the companies based in Malaga comply with them.

Starting out with all the companies, a search has been carried out to determine which of them are actually on line. Although we have not found any information source guaranteeing the analysis of $100 \%$ of the population, the total number of companies we have found reference to reaches 1,488 , which could represent over $95 \%$ of the total number of companies on line.

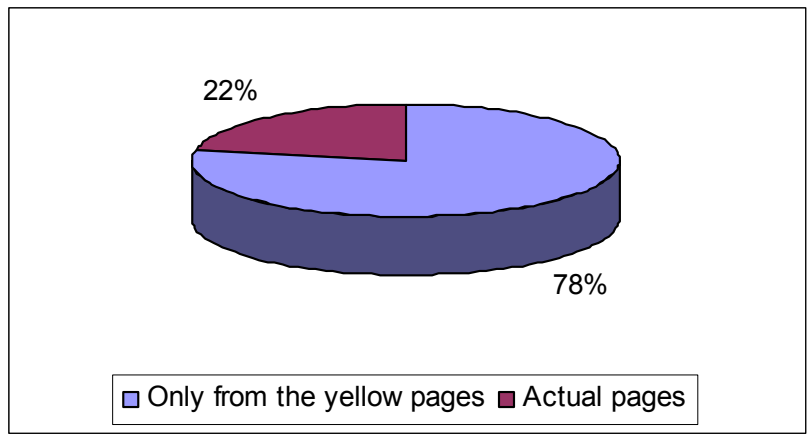

Figure 1: $\quad$ Malaga web pages analysed $(1,488)$.

Of these, $1,162(78.1 \%)$ limit their presence to merely a reference web page facilitated by the Yellow Pages; that is, these are companies with a minimally informative web page.

The other $326(21.9 \%)$ offer their own web pages. On further analysis we find that $42 \%$ of them (136) cannot be downloaded, which leaves only 190 companies (58\%) based in Malaga whose web pages can be analysed. Thus we find that only $12.7 \%$ of the pages found in our original search are left. 


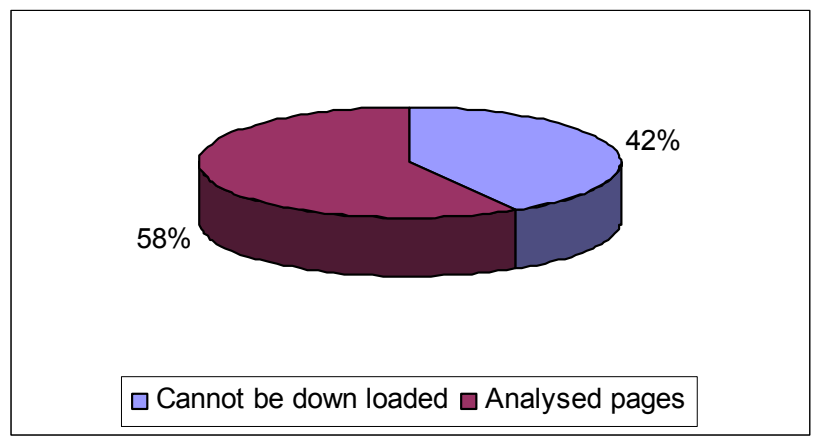

Figure 2: $\quad$ Web pages belonging to individual companies (326).

\subsection{Analysis based on the web page levels under study}

Based on the classification of levels in the web described in section 6, we know that level 1 is identified as an informative web site, level 2 refers to a web introducing its products, level 3 permits contact with clients, level 4 allows an order to be placed, level 5 includes those webs that include product delivery and level 6 those that also offer a service facilitating payment.

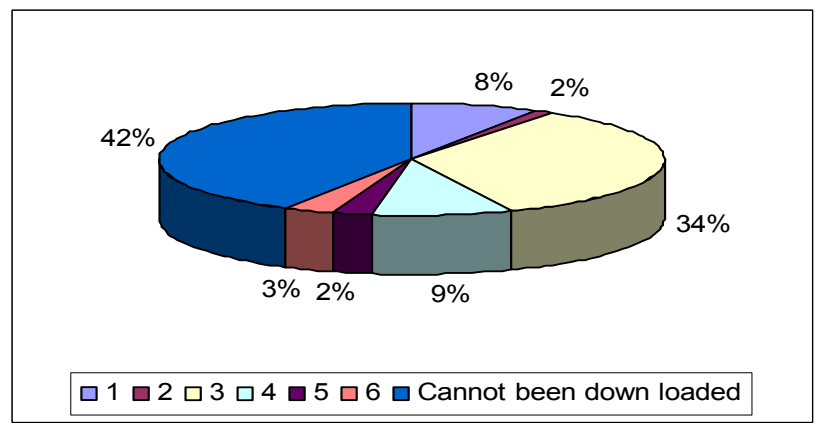

Figure 3: Level of web pages in Malaga. Distribution, keeping in mind that pages of a particular level include having complied with requirements for the previous lower levels.

The fact that a firm falls under one category or another depends greatly on the product involved. Companies offering products that can be distributed directly on line have a much better chance of reaching the sixth level. Of all the web pages analysed, 35 (11\%) offer virtual products.

This analysis has been carried out on two scales. On one hand, we have considered that reaching a determined level implies having achieved the lower levels, and on the other hand we have also decided it would be interesting to analyse each level independently, comparing the results of the whole group of web pages studied. 
Malaga web pages include 26 that are only informative and make up $8 \%$ of the pages analysed. Over a third of the web pages in Malaga's capital city reach the level that offers products and contact possibilities to the client. A study of the data reveals how much more complicated it is to reach transaction levels of products and payment. (See figure 3).

On observing figure 4 , we can see that it is logical for all webs to comply with the informative level, and nearly $100 \%$ of the web pages advertise the company's products while also allowing the client to carry out at least elementary information requests. The fact that these levels account for only about $50 \%$ is due to having to eliminate the percentage of web pages that could not be downloaded.

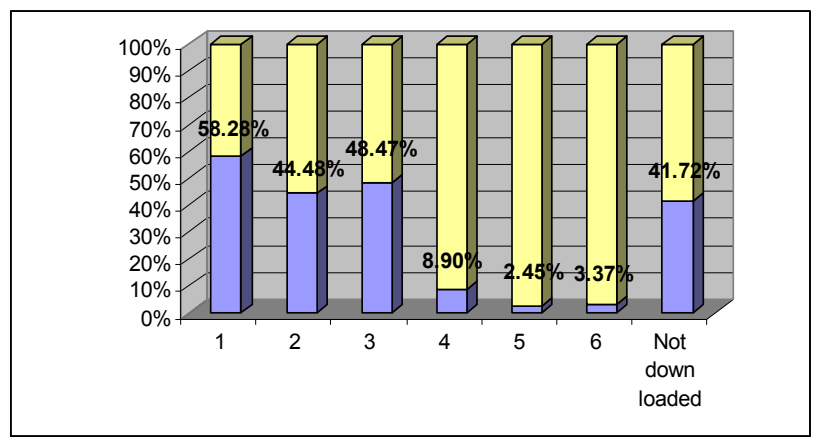

Figure 4: Level of web pages in Malaga. Levels achieved without taking into account if lower levels have been complied with.

\subsection{Analysis of the client data requested}

Twenty three companies request client data in order to establish contact (7\%).

The number of data requested ranges from 1 to 22 , the average number being 12. We have previously commented that it is not advisable to ask the client for too much information because it might cause the client to abandon, thus endangering the sale.

The only information necessary is that which is strictly required to carry out the sale, though in later sales more information can be requested and acquired.

The objective is to accumulate a database of clients in order to be able to carry out personalised sales, even if this database is only acquired gradually.

Although only 23 companies requested client data, 52 claimed to carry out CRM management (16\%).

\subsection{Analysis of payment facilities on the web}

The distribution of the forms of payment on web pages is shown in figure 5 .

Eighty per cent enter a safety guaranteed page when making the payment.

Thirty per cent offer different prices depending on the form of payment, cash on delivery being the riskiest and usually costing more. 


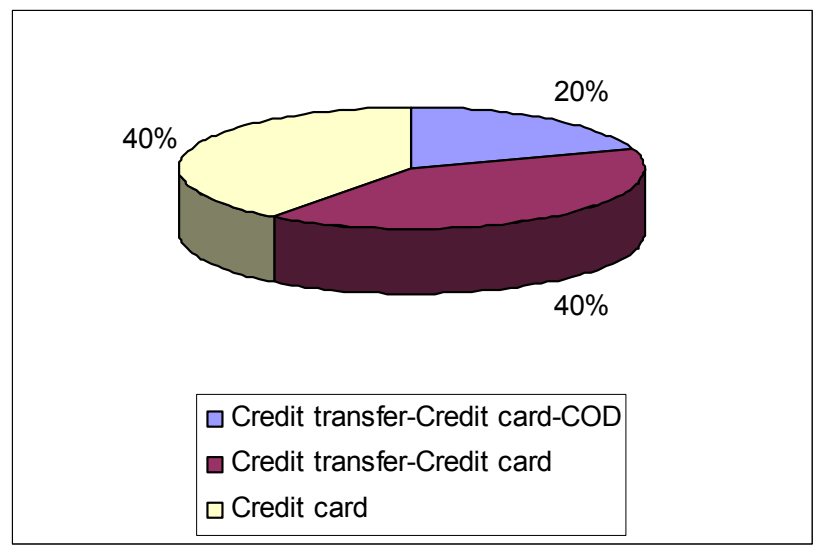

Figure 5: Distribution of the forms of payment on web pages.

\subsection{Analysis of the contact possibilities available on Internet, updating and the counting of visitors to the site}

102 companies can be contacted on line, which represents $31.29 \%$ of the web pages analysed. Responding to a general request for information, only 3 firms replied with an average response time of 8 hours, which is not a good response in terms of business transactions and client attention on the web.

We know that the Internet user hopes to be able to rapidly contact the page of interest, not only to be able to make a purchase, but also to be able to consult, expecting an almost immediate response. Thirty one percent of the web pages analysed allow queries to be made directly on the web pages.

The number of visitors is one way to measure the degree of interest in the web page. If this figure is not significant, it is preferable to omit it. In our study only 6 companies show the number of visitors.

Another aspect to be kept in mind is the extent to which the web is kept up to date. The same content all the time leads a visitor to look for another page to visit. Only 12 pages show the updated date of the page in question. All have been recently brought up to date except one belonging to the National Association of Long Distance Learning, which was last updated in 2002.

\subsection{Analysis of the degree to which other web pages are present on the web page and vice versa}

A web page usually contains publicity from the other companies it is usually linked to and this is possible only for the web pages that have a really high number of visitors.

Of the webs analysed, 53 companies include other companies' publicity on their pages. The average of adverts is 12.2. The connection to other pages is also not always due to publicity, but can be a question of hyperlinks of interest that the company is anxious to recommend. In this way, we find that $69(21.2 \%)$ of 
the 326 pages analysed in Malaga offer connections to other pages and the average number of these connections from one web page to others is 11 .

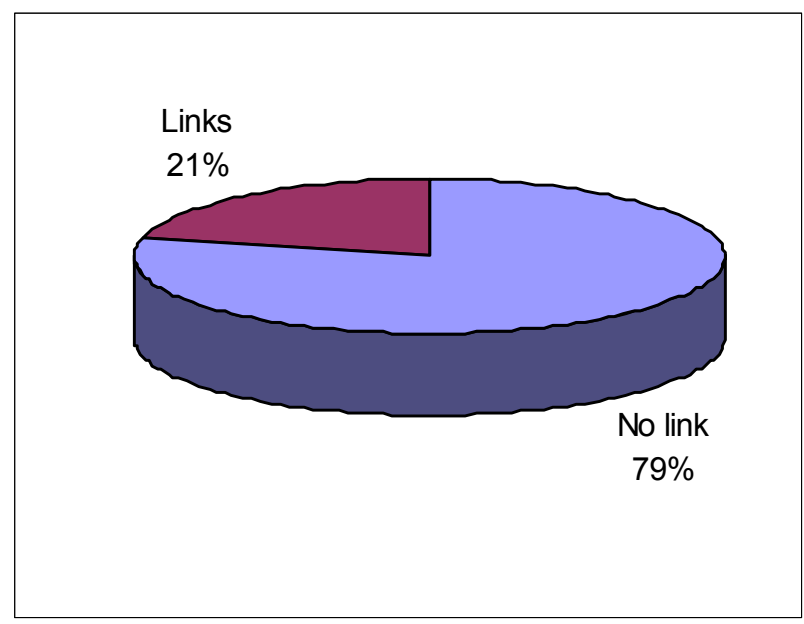

Figure 6: Links to other webs.

We also consider interesting to find how many webs have access to our page. In this case, we have similar results: 71 companies $(22 \%)$ have links from other webs with an average of about 48 links.

\subsection{Analysis of the services that webs carry out}

Through their webs, companies offer services to encourage clients to visit their page, even if these services are not directly related to their business activities.

Ninety one pages offer Internet clients additional services (28\%).

The services that they offer are distributed as presented in figure 7.

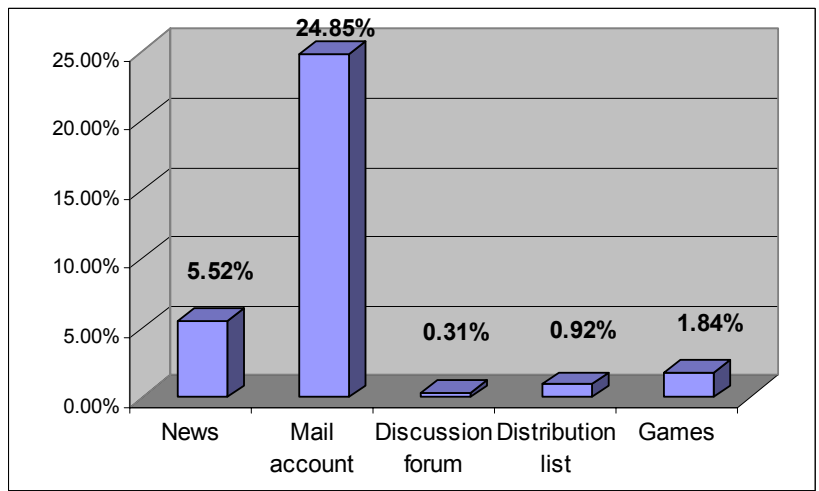

Figure 7: Distribution of the services offered by the webs. 
Obviously the most frequent service offered is a mail account $(25 \%)$, which is the most used and therefore a sure way to get clients to visit the page, even though companies are now thinking of offering this service for a charge.

Fifteen companies offer more than one service (4.6\%), and the most frequent combination is that of news and mail account (only seven pages).

\section{Conclusions}

The study carried out allows us to conclude that the growth of electronic commerce is undeniable as also is the growth of the presence of businesses on line. In order to analyse how these businesses introduce themselves via the web page and at what level, we can observe.

Those big companies that also belong to a sector favour this channel which, like financial entities or travel agencies, has many available webs that are corporative webs used by all branches. Normally they are very well kept web sites that comply with all the levels of electronic commerce.

On the other hand, small companies located exclusively in the capitals of a province are becoming conscious of the need to be available on line. Unfortunately, the small amount of attention that they pay to this media's potential reveals that currently they do not consider it to be an alternative route for distribution.

\section{Reference}

[1] AECE (Spanish Association of E-Commerce). Estudio sobre comercio electrónico 2004. http://www.aece.org/recursosclasifica.asp, 2005. 